\title{
Review
}

\section{Role of Alphasatellite in Begomoviral Disease Complex}

\author{
Muhammad Shafiq Shahid $^{\mathrm{a} *}$, Mehmoona Ilyas ${ }^{\mathrm{b}}$, Abdul Waheed $^{\mathrm{a}}$ and Rajarshi Kumar Gaur \\ ${ }^{a}$ Department of Biosciences, COMSATS Institute of Information Technology. Sahiwal 57000, Pakistan \\ ${ }^{b}$ Department of Biotechnology. University of Sargodha. Sargodha. Pakistan \\ cDepartment of Science. Faculty of Arts. Science and Commerce. Mody Institute of Technology and Science. \\ Lakshmangarh. Sikar-332311, Rajasthan. India
}

(received April 29,2015; revised June 17, 2015; accepted August 19,2015)

\begin{abstract}
A circular single stranded satellite, called as alphasatellite (initially identified as DNA-1), was characterised and confirmed to be associated with the Geminivirus begomovirus-betasatellite complexes. Alphasatellites are single stranded DNA (ssDNA) components, frequently accompanying with monopartite begomovirus or some time with bipartite begomovirus and/or betasatellite complex. The genome of alphasatellite DNAs are nearly half size of its helper virus genome and have no similarity with it. Furthermore. their function in begomovirus-betasatellite complex is still unclear. Recent advances in application of molecular tools helped in finding new viruses and allied satellite components that further help in advancing our understanding of this satellite DNA and this evolution.
\end{abstract}

Keywords. Geminivirus, begomovirus, alphasatellite

\section{Introduction}

Geminiviruses are an emerging group of plant viruses infecting most of economically important crops and ornamental plants throughout the world (Mansoor et al., 2003). Based on the host range. genome organisation and the vector, the Geminiviruses are classified into seven genera: Becurtovirus, Eragrovirus, Turncutovirus Topocuvirus, Curtovirus, Mastrevirus and Begomovirus (Adam et al., 2013; Brownet al., 2012). However, majority of the members of this family belongs to the genus Begomovirus and are spread by the whitefly, Bemisia tabaci (Briddon and Stanley. 2006). Viruses of this genus are distributed into two subgroups; bipartite begomoviruses with DNA-A+DNA-B genomes and monopartite begomovinuses that have a single DNA chain homologous to the DNA-A of bipartite begomovinus. DNA-A component of bipartite and the single component of monopartite begomovinuses (homologues to the DNA-A) encodes all viral functions required for virus replication control of gene expression and insect transmission. All begomoviruses have a potential stem-loop structure containing the nono-nucleotide sequence TAA/TATT/AC. necessary for replication.

In the last few years alphasatellite, the member of monopartite betasatellite/begomoviruses complexes, with a monomer of approximately 1375 nucleotide sequences. has attracted much attention and has become, probably, the most attentive scientific topic in the study of single stranded DNA (ssDNA) viruses. After the discovery of this satellite

*Author for correspondence; E-mail: shafiqinayatagmail.com. in 1999, more than 150 alphasatellite sequences have been deposited in database to date, however, very little is known about their function(s) during begomovirus-satellites infections. Examples of stability and maintaining of the alphasatellite component in natural infection with several begomoviruses complex have been shown several times since its first discovery, but without gaining further insights on their function (Shahid et al., 2014; Amrao et al., 2010; Mubin et al., 2010). Certainly, alphasatellites are nonessential for virus infection and appear to play no major role in the etiology of the infections with which they are associated (Mansoor et al., 1999). However, recent reports showed that some alphasatellites can attenuate disease symptoms caused by begomovirus-betasatellite complexes in the early stages of infection (Idris et al., 2011; Nawazul-Rehman et al., 2010). An overview of the origin and evolution of alphasatellites including the recent advances in understanding their molecular structure and their applications for reverse genetics are discussed.

General characteristics of alphasatellites. Despite that alphasatellites were discovered virtually 15 years ago, very little information is available up til now about its function(s). Alphasatellite molecules are mostly associated with monopartite begomovirus-betasatellite complex and also monopartite begomovirus can contain this component frequently (Shahid et al., 2014; Harimalala et al., 2013; Zhou. 2013; Zia-Ur-Rehman et al., 2013; Mubin et al., 2010; Dry et al., 1997). On the contrary, a few bipartite begomoviruses have been reported to be associated with alphasatellite (Satya et al., 2014; Paprotka et al., 2010). 
Initially, alphasatellites were found in association with the begomovirus-betasatellite complex from the old world (OW). Nevertheless, some distinctive alphasatellites were recently discovered to be associated with the new world (NW) begomovirus complex (Fiallo-Olive et al., 2012). Alphasatellites are believed to have evolved from satellitelike. Rep-encoding components associated with nanovinuses (Wyant et al., 2012; Briddon and Stanley 2006; Saunders and Stanley, 1999), another family of plant ssDNA vinuses. Alphasatellite was also found in association with a yellow vein disease in Ageratum convzoides (weeds) (Saunders and Stanley, 1999).

Genome, genomic organization and replication mechanism. The size of alphasatellite is between 1.300 bp to $1.400 \mathrm{bp}$ nucleotides in length and has three conserved domains: a hairpin structure, a rolling circle replication initiator protein (Rep) and a rich region (A-rich) (Fig. 1). The hairpin structure has a loop that includes a unique nono-nucleotide sequence, which usually varies from rest of the begomovinus components. TAG/TAT/TAC and differs from the TAA/TAT/TAC sequence of geminiviruses by one nucleotide ( $\mathrm{G}$ instead of $\mathrm{A}$ on a third nucleotide). In both begomovinuses and nanoviruses this sequence contains the origin of replication (ori) and is nicked by the rolling circle replication initiator protein to initiate viral DNA replication. The Rep of alphasatellite is the only single large open reading frame in the virion-sense which is predicted to encode a 315 amino acid product similar to the replication associated protein of nanoviruses. An adenine-rich region

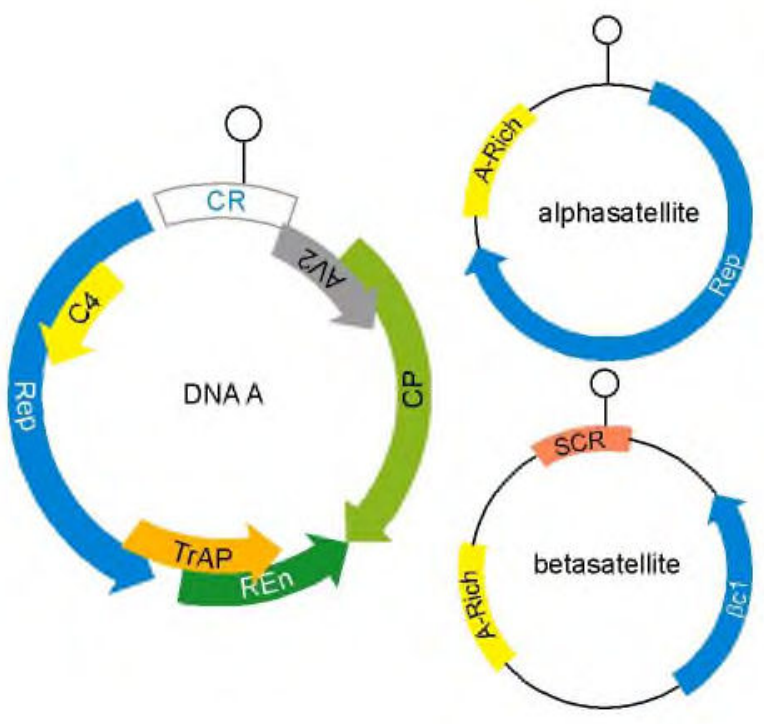

Fig. 1. Typical genome organisation of a monopartitebegomovirus satellites complex. (approximately $200 \mathrm{bp}$ with $45-52 \%$ adenine content) is also present, which is hypothesised to be a stuffer sequence that serves to fulfill the size constrain imposed by helper virus-mediated movement or encapsidation (Shahid et al., 2014; Zhou, 2013). Alphasatellite can replicate autonomously and its replication is specifically mediated by its Rep (Tao et al., 2004), while the replication of other components including betasatellite, is specifically mediated by the begomovirus Rep. This would suggest a difference in the begomovirus and alphasatellite replication origins. Recently. an alphasatellite associated with Okra leaf curl disease from West Africa (Kon et al., 2009) is highly divergent molecule from previously characterized alphasatellites (Fiallo-Olive et al., 2012; Saunders et al., 2002) indicating geographically isolated evolution of a West African lineage of these satellites. The geographical distribution and the genetic diversity of these satellites are consistent with a long term association with monopartite begomoviruses (Briddon and Stanley, 2006).

Genetic variability. Most of the monopartite begomovinusbetasatellite complex associated with alphasatellites have been characterised in the OW. Previous studies have shown that cotton leaf curl Multan virus (CLCuMV), cotton leaf curl Burewala virus (CLCuBV), tobacco leaf curl Pusa virus (TbLCuPuV). Ageratum yellow vein virus (AYVV). tobacco curly shoot virus (TbCSV). tomato yellow leaf curl virus (TYLCV). East African cassava mosaic Kenya virus (EACMKnV) and mungbean yellow mosaic virus (MYMV) are usually associated with alphasatellite (Satya et al., 2014; Shahid et al., 2014; Harimalala et al., 2013; Kumar et al., 2011; Singh et al., 2011; Mubin et al., 2010; Xie et al., 2010; Mansoor et al., 1999) (Fig. 2). Recently, different alphasatellites such as cassava mosaic (virus) alphasatellite, Gossypium darwinii symptomless alphasatellite. Vernonia yellow vein Fijian alphasatellite associated with EACMKnV, and CLCuBV, MYMV were isolated from different hosts i.e., cassava, cucurbits and legumes (Satya et al., 2014; Harimalala et al., 2013; ZiaUr-Rehman et al., 2013). Interestingly, a strain of TYLCV originating from Oman has been shown to be associated with an unusual alphasatellite (Ageratum yellow vein Singapore alphasatellite), the only alphasatellite that was previously reported from Singapore back in 1999 (Idris et al., 2011; Saunders and Stanley. 1999). Recently. Sida yellow vein China alphasatellite (SiYVCNA) has been identified in association with TYLCVV from main land Japan. However, the low levels of sequence divergence between all isolates of SiYVCNA suggests that this has only recently spread into Japan (Shahid et al., 2014). 


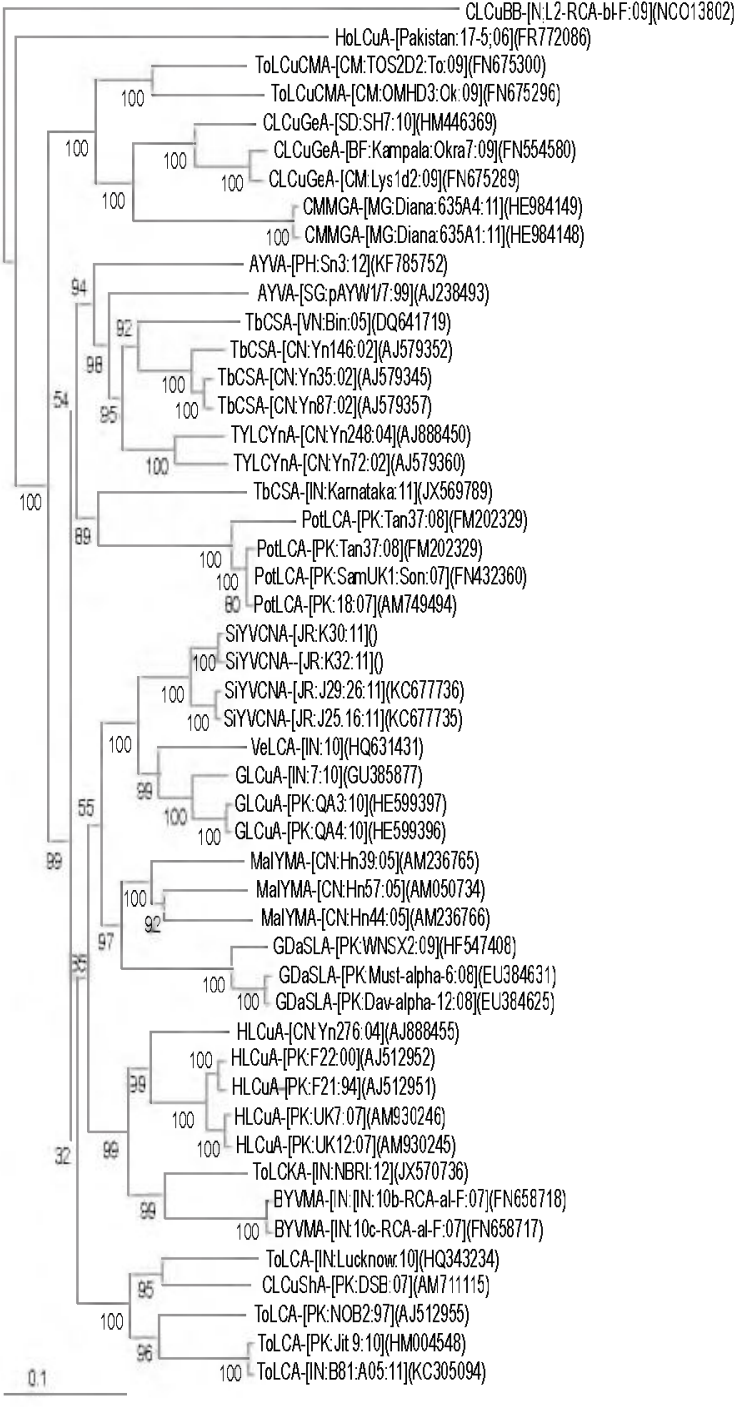

Fig. 2. Phylogenetic tree of commonly associated alphasatellites species.

Potential alphasatellite functions. Alphasatellites have no obvious contribution to symptoms induced by begomovirus-betasatellite disease complexes and appear to affect betasatellite replication but do not affect helper virus replication. However. some alphasatellites can attenuate disease symptoms caused by begomovirusbetasatellite complex in the early stages of infection. For example. Nawaz-ul-Rehman et al. (2010) have shown the alphasatellite Rep proteins encoded by two non-pathogenic alphasatellites. Gossypium darwinii symptomless alphasatellite (GDarSLA) and Gossvpium mustelinium symptomless alphasatellite (GMusSLA). They can interact with Cotton leaf curl Rajasthan virus (CLCuRaV) Rep proteins (Table 1). Betasatellites depend solely for replication on the Rep proteins encoded by their helper begomoviruses: binding between alphasatellite-Rep and helper virus Rep proteins may inhibit betasatellite replication and results in down regulated expression of $\beta \mathrm{C} 1$ and correspondent symptom amelioration. Also GDarSLA and GMusSLA alphasatellite-Reps have strong gene silencing suppressor activities (Nawaz-ul-Rehman et al., 2010). Although further investigations are required to prove whether alphasatellite-Reps encoded by other alphasatellites also have silencing suppressor activities. Recently, alphasatellites have been found in association with bipartite begomoviruses in Venezuela and Brazil (Zia-Ur-Rehman et al., 2013; Romay et al., 2010), respectively. The DNA2 type alphasatellite. a different alphasatellite (only two members) of this alphasatellite are found until now. one from Ageratum in Singapore and the other from tomato from Oman (Idris et al., 2011; Saunders et al., 2002). Although all these members contain conserved alphasatellite genome features. the DNA-2 type molecules are less homogeneous and have less than $50 \%$ nucleotide sequence identity with each other. The DNA-2 type alphasatellite identified in Oman can attenuate begomovirus symptoms and reduce accumulations of betasatellites (Idris et al., 2011). Further studies are needed to confirm whether these satellite molecules are replicated by their helper virus (es) and whether they have role in pathogenesis similar to those of betasatellites and some alphasatellites. New technologies like vector-enabled metagenomics and the recent circular DNA genomics (Ng et al., 2011) are anticipated to soon provide additional information about the field distributions of these novel satellites and their associated begomovinuses. The promising study about the function of this satellite indicate that the alphasatellite is most likely a molecular parasite of the helper begomovirus (Kon et al., 2009).

Viral vectors based on alphasatellites. Many plant viruses have been adapted into expression and VIGS vectors for external protein expression (Gleba et al., 2007) and silencing (Purkayastha and Dasgupta. 2009) of target genes in main crop plants. Recently, tobacco curly shoot alphasatellite (TbCSA) was successfully used to silence $\beta$-glucuronidase and the sulphur desaturase genes in different Nictoiana tabacum cultivars (Purkayastha and Dasgupta, 2009). Among that it can be used to investigate gene expression (or as an expression vector) on the entire host range of the begomoviruses/curtoviruses. Alphasatellite has some unique properties that make this component distinctive among other molecules. For example, it has Rep gene which makes the alphasatellite autonomous in replication. secondly it has a-rich region if deleted cannot effect on 
Table 1. Alphasatellite associated with monopartite-betasatellite complex

\begin{tabular}{|c|c|c|c|}
\hline Alphasatellite & Acc. no. & Associated Virus & Source \\
\hline Ageratum yellow vein alphasatellite & $\mathrm{AJ} 238493$ & Ageratum yellow vein virus (AYVV) & Saunders et al., 1997 \\
\hline Ageratum yellow vein India alphasatellite & JX570736 & Tomato leaf curl Karnataka virus & $\begin{array}{l}\text { Chatchawankanphanich and } \\
\text { Maxwell, } 2002\end{array}$ \\
\hline Ageratum yellow vein Kenya alphasatellite & AJ5 512960 & Diversity of alphasatellite & Briddon et al., 2004 \\
\hline Ageratum yellow vein Pakistan alphasatellite & FR772085 & Cotton leaf curl Burewala virus & Iqbal et al., 2013 \\
\hline Ageratum yellow vein Singapore alphasatellite & AJ416153 & AYVV & Saunders, 1999 \\
\hline Cassava mosaic Madagascar alphasatellite & HE984148 & East African cassava mosaic Kenya virus & Harimalala et al., 2013 \\
\hline Cleome leaf crumple alphasatellite & FN436007 & Cleome leaf crumple vinus & Paprotka et al, 2010 \\
\hline Cotton leaf curl Dabwali alphas atellite & AJ5 12957 & Diversity of alphasatellite & Briddon et al., 2004 \\
\hline Cotton leaf curl Gezira alphasatellite & FM164740 & AYVV & Leke et al., 2013 \\
\hline Croton yellow vein mosaic alphasatellite & FN658711 & Croton yellow vein mosaic virus & Zaffalon et al., 2011 \\
\hline Euphorbia yellow mosaic alphasatellite & FN436008 & Euphorbia yellow mosaic virus & Fernanda et al., 2011 \\
\hline Gossypium darwinii symptomless alphasatellite & EU384606 & Cototn leaf curl Rajasthan virus & Nawazul-Rehman et al., 2010 \\
\hline Hibiscus leaf curl alphasatellite & AJ512950 & Diversity of alphasatellite & Briddon et al., 2004 \\
\hline Hollyhock yellow vein symptomless alphasatellite & FR772086 & Hollyhock yellow vein virus & Saunders et al., 2000 \\
\hline Lantana yellow vein alphasatellite & $\mathrm{KC} 206075$ & Lantana yellow vein virus & Marwal et al., 2013a \\
\hline Malvastrum yellow mosaic alphasatellite & $\mathrm{AM} 050734$ & Malvastrum yellow mosaic virus & Guo et al., 2006 \\
\hline Malvastrum yellow mosaic Cameroon alphasatellite & FN675297 & $\begin{array}{l}\text { Tomato yellow leaf curl China virus } \\
\text { (ToLCCNV) }\end{array}$ & Leke et al., 2011 \\
\hline Melon chlorotic mosaic virus alphasatellite & FM163578 & Melonchlorotic leaf curl virus & Romay et al, 2010 \\
\hline Mesta yellow vein mosaic alphasatellite & JX183090 & Mesta yellow vein mosaic virus & Chatterjee et al., 2005 \\
\hline Okra leaf curl alphasatellite & AJ5 12954 & Diversity of alphasatellite & Briddon et al., 2004 \\
\hline Sida yellow vein Vietnam alphasatellite & DQ641718 & Sida yellow vein Vietnam virus & Ha et al., 2006 \\
\hline Tobacco curly shoot alphasatellite & AJ579361 & $\begin{array}{l}\text { Tomato yellow leaf curl China virus } \\
\text { (ToLCCNV) }\end{array}$ & Xie et al., 2010 \\
\hline Tomato yellow leaf curl China alphasatellite & AJ 579358 & ToLCCNV & Xie et al., 2010 \\
\hline Verbesina encelioides leaf curl alphasatellite & HQ631431 & Hollyhock yellow vein virus & Prajapat et al., 2011 \\
\hline Vernonia yellow vein Fujian alphasatellite & JF733780 & Vernonia yellow vein Fujian virus & Zulfiqar et al., 2012 \\
\hline Vinca yellow vein alphasatellite & KC206076 & Vinca yellow vein virus & Marwal et al., 2013b \\
\hline
\end{tabular}

its replication, lastly this molecule is quiet small and easy to manipulate. Shahid et al. (2009) have shown by agroinoculation studies with a-rich deleted cotton leaf curl Multan alphasatellite (CLCuMA) that this sequence is not required for the infectivity or maintenance of CLCuMA. Also CLCuMA has a wider host range and can successfully be maintained by a large number of diverse Begomovirus species. The ability to amplify itself is useful in a vector since it will increase the copy number (and thus also expression) of inserted sequences. deletion of a-rich region to increase the insert size and wider host range makes it a potentially useful vector (Tao and Zhou, 2004). The arich deleted CLCuMA was maintained in plants in the presence of a begomovirus. Although little is yet known about the maintenance of alphasatellites by begomoviruses. it is likely that high-level replication of these molecules is required for their maintenance, which depends upon its own Rep. There is no evidence for a (strong) selection mechanism for maintenance of alphasatellites. Maintenance of alphasatellites can simply be a selection of numbers; plants containing high levels of the satellite allow cell-tocell movement by the virus encoded movement proteins or infection to the next plant by the vector of the helper begomovirus. Tao and Zhou (2004) used modified CLCuMA for virus induced gene silencing vector in plants. The same vector was used to successfully silence the chelates gene (ChlI). One of the advantages of an alphasatellite vector, over many of the other vectors, is that it can, at least in theory, be used with different Begomovirus or even Curtovirus (Saunders et al. 2002).

Recent research advances. Recent progresses in research comprises of the construction of the alphasatellite-based vectors. the development of the first VIGS system for different agricultural crops, the description of new alphasatellites, improvement in diagnostics, and new information on the begomovirus-satellite complex.

\section{Conclusion}

The role that alphasatellites play in begomovirus-satellite disease complex is still generally unidentified. The recent advancement and emerging potential of Next Generation Sequencing approaches will undoubtedly contribute considerably to the elucidation of the aetiology of many of these alphasatellite associated diseases. The fairly recent discovery of alphasatellite in Japan (Shahid et al., 2014) 
and its presence in papaya gardens in Nepal (Shahid et al., 2013) suggest that its occurrence and possible role in disease in other agricultural-producing regions need to be investigated. What effect the presence of an alphasatellite and the defective allied component may have on future begomovirus-betasatellite complex is not clear.

Whereas outdated research focused on the detection and characterisation of prevailing and new begomovirussatellite complexes, we believe research on (i) the elucidation of the etiology of these disease complexes (ii) the development of resistance using non-transgenic approaches, and (iii) studies on the molecular interaction of alphasatellites and their helper viruses with their original host. As efficient tools are being developed now, future research with begomoviruses, as well as with all other whitefly-vectoring viruses, has to move from typical (model) plants like Nicotiana benthamiana towards other host plants to allow the study of symptomology. pathogenicity, host-plant response and viral determinants of vector transmission in their natural host.

\section{References}

Adams, M.J., King. A.M.Q., Carstens, E.B. 2013. Ratification vote on taxonomic proposals to the International Committee on Taxonomy of Viruses. Archives of Virology, 158: 2023-2030.

Amrao, L., Irnip. I., Shahid. M.S., Briddon. R.W.. Mansoor, S. 2010. Cotton leaf curl disease in resistant cotton is associated with a single begomovirus that lacks an intact transcriptional activator protein. Virus Research, 152: 153-163.

Briddon. R.W.. Stanley, J. 2006. Subviral agents associated with plant single-stranded DNA viruses. Virology, 344: 198-210.

Briddon. R.W., Bull, S.E., Amin. I.. Mansoor, S.. Bedford, I.D.. Rishi, N., Siwatch, S.S., Zafar, M.Y.. Abdel-Salam, A.M., Markham, P.G. 2004. Diversity of DNA 1; a satellite-like molecule associated with monopartite begomovirus-DNA complexes. Virology, 324: 462-474.

Brown. J.K., Fauquet, C.M., Briddon, R.W., Zerbini. M., Moriones, E., Navas-Castillo, J. 2012. Geminiviridae. In: Virus Taxonomy - Ninth Report of the International Committee on Taxonomy of Viruses, King. A.M.Q.. Adams. M.J.. Carstens. E.B.. Lefkowitz. E.J. (eds.). pp. 351-373. Associated Press. Elsevier Inc.. London. Waltham. San Diego. USA.

Chatterjee. A., Roy, A., Padmalatha, K.V., Malathi.
V.G., Ghosh. S.K. 2005. Occurrence of a Begomovirus with yellow vein mosaic disease of mesta (Hibiscus cannabinus and Hibiscus sabdariffa). Australasian Plant Disease Notes, 34: 609-610.

Chatchawankanphanich, O., Maxwell, D.P. 2002. Tomato leaf curl Karnataka virus from Bangalore, India. Appears to be a Recombinant Begomovirus. Phytopathology, 92: 637-645.

Dry, I.B., Krake, L.R., Rigden, J.E., Rezaian, M.A. 1997. A novel subviral agent associated with a geminivirus: The first report of a DNA satellite. In: Proceedings of the National Academy of Sciences, 94: 7088-7093.

Fermandes. F.R.. Albuquerque. L.C.. de Oliveira. C.L.. Cruz, A.R., da Rocha. W.B., Pereira. T.G., Naito. F.Y., Dias Nde, M., Nagata. T., Faria, J.C., Zerbini, F.M., Aragao, F.J., Inoue-Nagata, A.K. 2011. Molecular and biological characterization of a new Brazilian begomovirus, Euphorbia yellow mosaic virus (EuYMV), infecting Euphorbia heterophylla plants. Archives of Virology, 156: 2063-2069.

Fiallo-Olive, E., Martinez-Zubiaur, Y., Moriones, E., Navas-Castillo, J. 2012. A novel class of DNA satellites associated with New World begomoviruses. Virology, 426: 1-6.

Guo, X., Zhou. X. 2006. Molecular characterization of a new begomovirus infecting Sida cordifolia and its associated satellite DNA molecules. Virus Genes, 33: 279-285.

Gleba, Y., Klimyuk. V.. Marillonnet, S. 2007. Viral vectors for the expression of proteins in plants. Current Opinion in Biotechnology, 18: 134-141.

Ha, C., Coombs, S., Revill, P., Harding, R., Vu, M., Dale, J. 2006. Corchorus yellow vein virus, a new world geminivirus from the old world. Journal of General Virology, 87: 997-1003.

Harimalala, M., De-Bruyn, A., Hoareau, M., Andrianjaka, A., Ranomenjanahary. S., Reynaud. B.. Lefeuvre. P.. Lett. J. 2013. Molecular character, station of a new alphasatellite associated with a cassava mosaic geminivirus in Madagascor. Archives of Virology, 158: 1829-1832.

Idris. A.M.. Shahid. M.S.. Briddon, R.W., Khan. A.J.. Zhu. J.K.. Brown. J.K. 2011. An unusual alphasatellite associated with monopartite begomoviruses attenuates symptoms and reduces betasatellite accumulation. Journal of General Virology, 92: 706-717.

Iqbal, M.J., Hussain, W., Zia-Ur-Rehman, M., Hameed, U.. Haider, M.S. 2013. First report of chilli leaf 
curl virus and associated alpha- and beta-satellite DNAs infecting nettle weed (Urtica dioica L.) in Pakistan. Plant Disease, 1-2.

Kon. T., Rojas. M.R., Abdourhamane. I.K.. Gilbertson. R.L. 2009. Roles and interactions of begomoviruses and satellite DNAs associated with okra leaf curl disease in Mali. West Africa. Journal of General Virology, 90: 1001-1013.

Kumar, A., Snehi, S.K., Raj. S.K., Kumar, J., Khan. J.A. 2011. Association of Cotton leaf curl Burewala virus and its satellite molecules with leaf distortion symptoms of cotton in India. New Disease Reports, 24: $18-18$.

Leke. W.N., Sattar, M.N., Ngane. E.B., Ngeve. J.M. Kvaraheden. A.. Brown. J.K.2013. Molecular characterization of begomoviruses and DNA satellites associated with okra leaf curl disease in Cameroon. Virus Research, 174: 116-125.

Leke, W.N., Kvarnheden, A., Ngane. E.B., Titanji, V.P., Brown. J.K. 2011. Molecular characterization of a new begomovirus and divergent alpha satellite from tomato in Cameroon. Archives of Virology, 156: $925-928$.

Marwal, A., Sahu. A., Sharma. P., Gaur, R.K. 2013. Molecular characterizations of two begomoviruses infecting Vinca rosea and Raphanus sativus in India. Virologica sinica, 28: 53-56.

Marwal, A., Sahu, A.K.,Gaur, R.K. 2013. Molecular characterization of begomoviruses and DNA satellites associated with a new host Spanish flag (Lantana camara) in India. Indian Journal of Virology, 1-5.

Mansoor, S., Briddon, R.W., Zafar. Y., Stanley. J. 2003. Geminivirus disease complexes: An emerging threat. Trends in Plant Sciences, 8: 128-134.

Mansoor, S., Khan, S.H., Bashir, A., Saeed, M., Zafar, Y., Malik, K.A., Briddon, R.W., Stanley. J.. Markham, P.G. 1999. Identification of a novel circular single-stranded DNA associated with cotton leaf curl disease in Pakistan. Virology, 259: 190199.

Mubin. M., Shahid. M.S., Tahir, M.N., Briddon, R.W.. Mansoor, S. 2010. Characterization of begomovirus components from a weed suggests that begomoviruses may associate with multiple distinct DNA satellites. Virus Genes, 40: 452-457.

Nawaz-ul-Rehman. M.S., Nahid, N., Mansoor, S.. Briddon. R.W.. Fauquet. C.M. 2010. Posttranscriptional gene silencing suppressor activity of two non-pathogenic alphasatellites associated with a begomovirus. Virology, 405: 300-308.

Ng. T.F. Duffy, S., Polston. J.E., Bixby, E., Vallad. G.E.. Breitbart, M. 2011. Exploring the diversity of plant DNA viruses and their satellites using vector-enabled metagenomics on white flies. PLoS One, 6: e19050.

Paprotka, T., Metzler, V., Jeske, H. 2010. The first DNA 1-like alphasatellites in association with New World begomoviruses in natural infections. Virology, 404: 148-157.

Prajapat. R.. Marwal. A.. Bajpai, V.. Gaur, R.K. 2011. Genomics and proteomics characterization of alpha satellite in weed associated with begomovirus. International Journal of Plant Pathology, 2: 1-14.

Purkayastha, A.. Dasgupta. I. 2009. Virus-induced gene silencing: a versatile tool for discovery of gene functions in plants. Plant Physiology and Biochemistry, 47: 967-976.

Romay, G., Chirinos, D., Geraud-Pouey, F.. Desbiez. C. 2010. Association of a typical alphasatellite with a bipartite New World begomovirus. Archives of Virology, 155: 1843-47.

Satya, V.K., Malathi, V.G., Velazhahan, R., Rabindran. R., Jayamani, P., Alice, D. 2014. The DNA-1 like alphasatellites in association with the bipartite Mungbean yellow mosaic virus in natural infections. Archives of Phytopathology and Crop Protection, 47: 194-204.

Saunders, K.. Bedford. I.D.. Stanley, J. 1997. Adaptation from whitefly to leafhopper transmission of an autonomously replicating nanovirus-like DNA component associated with Ageratum yellow vein disease. Journal of General Virology, 83: 907-913.

Saunders, K., Bedford. I.D., Briddon. R.W., Markham. P.G., Wong. S.M., Stanley, J. 2000. A unique virus complex causes Ageratum yellow vein disease. Proceedings of the National Academy of Sciences USA, 97: 6890-6895.

Saunders, K.. Stanley. J. 1999. A nanovirus-like DNA component associated with yellow vein disease of Ageratum conyzoides: evidence for interfamilial recombination between plant DNA viruses. Virology, 264: 142-152.

Shahid. M.S., Ikegami, M., Waheed, A., Briddon, R.W., Natsuaki, K.T. 2014. Association of an alphasatellite with tomato yellow leaf curl virus and ageratum yellow vein virus in Japan is suggestive of a recent introduction. Viruses, 6: 189-200.

Shahid. M.S., Khatri-Chhetri. G.B.. Briddon. R.W. Natsuaki. K.T. 2013. Complete nucleotide sequence 
of a monopartite begomovirus and associated satellites infecting Carica papaya in Nepal. Virus Genes, 46: 581-584.

Shahid. M.S., Ali, L.. Wajid, S. 2009. The function of the a-rich region of the alphasatellite associated with the cotton leaf curl disease in Pakistan. EurAsia Journal of Bio Sciences, 3: 152-156.

Singh, M.K., Singh, K., Haq. Q.. Mandal, M.R.B.. Varma, A. 2011. Molecular characterization of Tobacco leaf curl Pusa virus. a new monopartite begomovirus associated with tobacco leaf curl disease in India. Virus Genes, 43: 296-306.

Tao. X.R.. Zhou. X.P. 2004. A modified viral satellite DNA that suppresses gene expression in plants. Plant Journal, 38: 850-860.

Tao, X.. Qing. L.. Zhou. X. 2004. Function of a-rich region in DNA $\beta$ associated with Tomato yellow leaf curl China virus. Chinese Science Bulletin, 9: 1490-1493.

Wyant, P.S., Strohmeier, S., Schafer. B., Krenz, B.. Assuncao, I.P. 2012. Circular DNA genomics (circomics) exemplified for geminiviruses in bean crops and weeds of northeastern Brazil. Virology, 427: 151-157.

Xie, Y., Wu, P., Liu, P., Gong. H., Zhou, X. 2010. Characterization of alphasatellites associated with monopartite begomovirus/betasatellite complexes in Yunnan. China. Virology Journal, 7: 178.

Zhou, X. 2013. Advances in understanding begomovirus satellites. Annual Review of Phytopathology, 51: 357-381.

Zaffalon, V., Mukherjee, S.K., Reddy, V.S.. Thompson. J.R.. Tepfer, M. 2011. A survey of geminiviruses and associated satellite DNAs in the cotton growing areas of northwestern India. Archives of Virology, $1-13$.

Zulfiqar, S., Shahnawaz, S., Ali, M., Bhutta, A.M. Iqbal. S., Hayat. S., Qadir. S., Latif, M., Kiran. N.. Saeed, A., Ali, M., Iqbal, F. 2012. Detection of Babesia bovis in blood samples and its effect on the hematological serum biochemical profile in large ruminants from Southern Punjab (Pakistan). Asian Pacific Journal of Tropical Biomedicine, 2: 104-108. 